Seção Temática: Balanço do Fundeb

Volume 10 - $2020 \mid$ n. 30

\title{
Panorama Geral do Financiamento da Educação na Rede Estadual do Piauí, pós instituição do Fundeb no Brasil ${ }^{1}$
}

\author{
Samara de Oliveira Silva \\ Universidade Estadual do Piauí (UESPI), Teresina/PI - Brasil \\ Theresa Maria de Freitas Adrião \\ Universidade Estadual de Campinas (UNICAMP), Campinas/SP - Brasil \\ Lucine Rodrigues Vasconcelos Borges de Almeida
}

Secretaria de Educação e Cultura do Estado do Piauí (SEDUC-PI), Teresina/PI - Brasil

\section{Resumo}

Este artigo tem por objetivo investigar o financiamento da educação na rede estadual do Piauí, destacando a composição das receitas, a aplicação de recursos de impostos e transferências em Manutenção e Desenvolvimento de Ensino (MDE) e o movimento do FUNDEB, de 2007 a 2017. A abordagem metodológica adotada foi de natureza qualitativa, com base em pesquisa documental, mediante adoção de fontes primárias e secundárias. A pesquisa revelou que a composição das receitas no estado tem maior participação do ICMS e do FPE; que embora seja previsto na Constituição Estadual do Piauí a aplicação mínima de 30\%, não houve respeito a esse dispositivo constitucional de 2007 a 2017 e que a rede estadual tem perdas significativas no sistema de partilha do FUNDEB, cujos valores não são compensados pela complementação da União.

Palavras-chave: Política Educacional. Direito à Educação. Financiamento da Educação. FUNDEB.

\section{Overview of Education Funding in the Piaui State Network, after the institution of Fundeb in Brazil}

\begin{abstract}
This article aims to investigate the financing of state education in Piauí, highlighting a composition of revenues, an application of tax resources and transfers in Maintenance and Development of Education (MDE) and the Fundeb movement, from 2007 to 2017. The methodological approach adopted was of a qualitative nature, based on documentary research, using the adoption of primary and secondary sources. A survey revealed that the composition of revenues in the State has a greater participation of ICMS and FPE; that although a minimum application of $30 \%$ is foreseen in the Piauí State Constitution, there was no respect for the constitutional provision from 2007 to 2017 and that the state network has significant losses in the Fundeb sharing system, which values are not offset by the Union's complement.
\end{abstract}

Keywords: Educational Policy. Right to Education. Education Funding. Fundeb.

\footnotetext{
1 Artigo decorrente da pesquisa de Samara Silva (2019). No âmbito do Grupo de Estudos e Pesquisas em Política Educacional (GREPPE-UNICAMP), sob a orientação de Theresa Adrião.
} 
Panorama Geral do Financiamento da Educação na Rede Estadual do Piauí, pós instituição do Fundeb no Brasil

\section{Introdução}

A Constituição Federal de 1988 (CF/1988) define a educação como direito social, responsabilizando o Estado por ofertá-la mediante a vinculação de receitas (CURY, 2007), conforme prescrito no artigo 212, nos seguintes termos: "A União aplicará, anualmente, nunca menos de dezoito, e os Estados, o Distrito Federal e os Municípios vinte e cinco por cento, no mínimo, da receita resultante de impostos, compreendida a proveniente de transferências, na manutenção e desenvolvimento do ensino" (BRASIL,1988).

A aplicação dos recursos da educação está regulamentada na Lei de Diretrizes e Bases da Educação Nacional (LDB n. 9.394/96), no capítulo relacionado ao financiamento da educação, artigos 68 a 77, os quais estabelecem as fontes e os critérios de uso dos recursos. O artigo 68 especifica que as fontes de recursos públicos para a educação são originárias da:

I - Receita de impostos próprios da União, dos Estados, do Distrito Federal e dos Municípios; II - receita de transferências constitucionais e outras transferências; III receita do salário-educação e de outras contribuições sociais; IV - receita de incentivos fiscais; V - outros recursos previstos em lei (BRASIL, 1996).

As principais fontes que financiam a educação pública no Brasil são os impostos e a contribuição social Salário-Educação. Ao indicar a possibilidade de outras contribuições sociais, incentivos fiscais e outros recursos previstos em lei, a LDB/1996 apresenta potencial importante de ampliação de recursos, os quais são necessários inclusive para o alcance do cumprimento das metas do Plano Nacional de Educação - PNE 2014-2024 (CARA, 2016).

A principal política de financiamento da educação básica no contexto atual é o Fundo de Manutenção e Desenvolvimento da Educação Básica e de Valorização dos Profissionais da Educação (FUNDEB), criado pela Emenda Constitucional n. 53/2006, regulamentado pela Lei n. 11.494/2007 e pelo Decreto n. 6.253/2007, com vigência de 2007 a 2020, sucessor do Fundo de Manutenção e Desenvolvimento do Ensino Fundamental e de Valorização do Magistério (FUNDEF), que vigorou de 1996 a 2006.

Para Pinto (2014), a instituição da política de fundos para o financiamento da educação, inaugurada com o FUNDEF, tinha como fundamento a redução das disparidades entre os gastos dos estados e dos municípios com o Ensino Fundamental, em suas respectivas redes, dentro de uma mesma Unidade da Federação, e entre as diferentes Unidades, por meio da complementação da União.

Ressalta-se que a complementação da União ao Fundo é essencial para a redução das desigualdades educacionais por contribuir para o aumento do Valor Aluno Ano (VAA) das redes de ensino de menor capacidade tributária, as quais demandam políticas de combate às desigualdades pela distribuição da riqueza e da renda, com protagonismo da União, tendo em vista que em regiões como Norte e Nordestes predominam, em razão dos déficits econômicos e da injustiça fiscal e tributária, a baixa arrecadação de recursos próprios.

O FUNDEB, mantendo a lógica do Fundo anterior, incluiu toda a Educação Básica e aumentou a complementação da União, contribuindo para aperfeiçoar o pacto federativo existente. Não obstante, tem-se as críticas. Araújo (2013), por exemplo, ressalta que a política de Fundos não representou, em termos globais, mais recursos para a educação, nem redistribuição de recursos entre os estados e regiões brasileiras, o que contribuiria para a 
Panorama Geral do Financiamento da Educação na Rede Estadual do Piauí, pós instituição do Fundeb no Brasil

redução das desigualdades regionais, mas somente uma política de redistribuição entre o próprio estado e seus municípios.

Pinto (2007, p. 888) ainda chama a atenção para o fato de que "[...] essa política de fundos tende a levar os entes federados a buscar uma maior racionalização dos recursos, proporcionando o aumento do número de alunos por sala e a possibilidade de subfinanciar escolas de pequeno porte", impactando na qualidade da educação. Ademais, no que tange à relação entre o público e o privado na gestão dos recursos educacionais, Pinto (2007) ressalta que na versão final do FUNDEB "foram incluídas as matrículas da educação infantil e da educação especial da rede conveniada sem fins lucrativos" (PINTO, 2007, p. 888).

Não obstante as críticas, o FUNDEB amenizou parte dos problemas do Fundo anterior, principalmente por contemplar todas as etapas e modalidades da educação básica e por elevar a participação da União na complementação do Fundo aos estados que não alcançassem o valor mínimo por aluno definido nacionalmente, como foi o caso do Piauí durante os 14 anos de FUNDEB.

Este artigo tem por objetivo investigar o financiamento da educação na rede estadual do Piauí, destacando a composição das receitas; a aplicação de recursos de impostos e transferências em Manutenção e Desenvolvimento de Ensino (MDE) e o movimento do FUNDEB, de 2007 a 2017.

A abordagem metodológica adotada foi de natureza qualitativa, com base em pesquisa documental, mediante adoção de fontes primárias e secundárias. As fontes foram os dados oficiais coletados junto ao Sistema de Informações sobre Orçamentos Públicos em Educação (SIOPE) e à Secretaria de Fazenda do Piauí (SEFAZ/PI), relativos ao período de 2007 a 2017. Os dados financeiros foram corrigidos pelo Índice Nacional de Preços ao Consumidor (INPC) do IBGE, para viabilizar as comparações dos valores na série histórica adotada pelo estudo.

O artigo é composto por três seções, além desta introdução. Na primeira, são sistematizados os principais aspectos que influenciaram o financiamento da educação no Brasil pós Constituição Federal de 1988. Na segunda, é apresentado o panorama do financiamento da educação na rede estadual de educação do Piauí. Na terceira, são tecidas as considerações finais do artigo.

\section{Aspectos centrais do financiamento da Educação, pós Constituição Federal de 1988}

O financiamento da educação no Brasil constitui-se em um dos maiores desafios no campo das políticas públicas, tanto pelo enorme contingente de pessoas ainda excluídas do direito à educação, quanto pelos problemas gerados pela malversação e clientelismo político no trato dos recursos públicos para educação ao longo de nossa história. Esses problemas têm ocasionado a desestruturação do sistema educacional, que se revela incapaz de responder condignamente às necessidades de escolarização básica necessária para a formação do cidadão e da cidadã.

A ampliação dos recursos para a manutenção do sistema educacional brasileiro tem importância destacada, especificamente para os estados e municípios que têm a obrigação de prover o atendimento para mais de 48 milhões estudantes, da educação infantil ao ensino médio, em redes públicas que ainda precisam de expansão da oferta educacional. Para Pinto 
(2018a), "aos governos estaduais e prefeituras, cabe a oferta de cerca de $80 \%$ das matrículas e das despesas". Contudo, essa responsabilidade tem incompatibilidade com a lógica da arrecadação dos recursos entre os entes pois é a União "[...] quem mais arrecada impostos, o governo federal só coloca dois de cada dez reais do gasto público na Educação Básica" (PINTO, 2007, p. 865) ${ }^{2}$.

O mecanismo que assegura a relação direta entre recursos arrecadados e investimento em educação é a vinculação. Como resultado do processo de mobilização social, conseguiuse assegurar, na CF/1988, a vinculação de impostos da base tributária brasileira para financiamento da educação. Essa vinculação constitucional de recursos financeiros para a educação tem sido, praticamente, o único meio de assegurar recursos públicos para a Manutenção e Desenvolvimento do Ensino (MDE), segundo autores como Melchior (1987), Almeida (1989), Monlevade (1997), Pinto (2000), Pinto e Adrião (2006), Oliveira e Adrião (2006; 2013), Castro, (2001), Davies (2006), entre outros.

O artigo 69 da LDB n. 9.394/96, determina que "a União aplicará, anualmente, nunca menos de dezoito, e os Estados, o Distrito Federal e os Municípios, vinte e cinco por cento, ou o que consta nas respectivas Constituições ou Leis Orgânicas, da receita resultante de impostos, compreendidas as transferências constitucionais, na manutenção e desenvolvimento do ensino público" (BRASIL, 1996, grifos nossos). A redação dada pelo artigo 69 da LDB é um avanço, porque reconhece e legitima a ampliação do percentual de vinculação, por parte de estados e municípios, em suas constituições estaduais ou leis orgânicas (OLIVEIRA, 2007).

Castro (2001, p. 12) ressalta que a vinculação é uma conquista importante para o direito à educação, preservada em períodos democráticos, embora com a criação de estratégias governamentais para desvincular os recursos que afetam, também, a educação, como ocorrido com o Fundo de Social de Emergência (FSE), Fundo de Estabilização Fiscal (FEF) e Desvinculação dos Recursos da União (DRU) ${ }^{3}$.

O financiamento da educação pública sofreu os efeitos da instituição desse mecanismo de desvinculação das Receitas da União. Em 2000 foi retirada da base de cálculo uma série de recursos: o Imposto sobre Operações de Crédito, Câmbio e Seguros (IOF Ouro); Imposto de Renda (IR) pago por estados e municípios; os Fundos de Participação Social dos estados, do Distrito Federal e dos municípios (FPE e FPM); os Fundos Constitucionais de Financiamento do Norte, Nordeste e Centro-Oeste (FNO, FNE e FCO); o Imposto sobre

2 Deve haver um agravamento dessa situação diante da aprovação da Emenda Constitucional n. 95/2016, que estabelece um novo regime fiscal com limites de gastos para o governo federal com despesas primárias até 2036. Essa nova regulamentação leva a uma redução de investimentos em educação, enfraquecendo ações capazes de avançar na garantia de melhores condições de trabalho do professor. Dentre outras implicações, a EC/95 compromete o cumprimento da Meta 20 do PNE 2014-2024, paralisando todas as ações propostas nesse plano (Nota Técnica Fineduca, 2016).

3 O Fundo Social de Emergência (FSE), criado por meio da Emenda Constitucional de Revisão $n^{\circ} 01$, de $1^{\circ}$ de março de 1994, tinha como principal finalidade a racionalização do orçamento federal. Superado os dois anos da FSE, foram criados o Fundo de Estabilização Fiscal (FEF) (EC n 10/1996 e EC n 17/1997, prorrogação) e a Desvinculação de Recursos da União (DRU) (EC n 27/2000, EC n 42/2003, EC n 56/2007, EC n 68/2011), todas desvinculando $20 \%$ de recursos federais de impostos e contribuições. A última aprovação, pela EC $n^{\circ}$ 93/2016, prorrogou a DRU até 2023, aumentando a alíquota de desvinculação para $30 \%$. O argumento que prevalece para a manutenção desse dispositivo, em todas as edições, é o objetivo de "flexibilização da alocação de recursos para realizar os investimentos necessários para garantir a continuidade do crescimento do país" (BRASIL, 2011). 
Panorama Geral do Financiamento da Educação na Rede Estadual do Piauí, pós instituição do Fundeb no Brasil

Produtos Industrializados (IPI) exportações, transferido para os estados e o Distrito Federal; bem como a arrecadação da contribuição social Salário-Educação a que se refere o art. 212, $\S 5^{\circ}$, da Constituição. Além disso, a Emenda Constitucional n. 31, de 2000, excluiu os recursos do Fundo de Combate e Erradicação da Pobreza do cálculo das desvinculações (PINTO, 2006).

Em 2003, através da Emenda Constitucional n 42/2003 - conhecida como minirreforma tributária, a DRU foi prorrogada até o dia 31 de dezembro de 2007. Essa Emenda determinou que os instrumentos de desvinculação de receitas não reduziriam a base de cálculo das transferências aos estados, Distrito Federal e municípios na forma dos artigos 153, § 50; 157 , I; 158, I e II; e 159, I, a e b; e II, da Constituição, bem como a base de cálculo das destinações a que se refere o art. 159, I, c, da Constituição (PINTO, 2006).

A Emenda ainda ampliou o escopo de atuação da DRU, passando a incluir as receitas provindas de contribuições de intervenção no domínio econômico (CIDE) e daquelas que viessem a ser criadas no futuro, com o intuito de permitir que a DRU atingisse a CIDE combustíveis a partir do exercício de 2004 (PINTO, 2006).

Em 2007, pela Emenda Constitucional n. 56/2007, garantindo sua vigência até 31 de dezembro de 2011, prorrogou-se, o mecanismo "transitório" de desvinculação, justificada pelo objetivo de manter um grau mínimo de autonomia na definição de prioridades e na gestão orçamentária. Nesse período, decorrente de pressões sobre o governo para retirar a incidência da DRU sobre os recursos MDE, através da Emenda Constitucional n. 59, de 11 de novembro de 2009, determinou-se a redução progressiva do percentual da DRU incidente sobre os recursos de MDE (PINTO, 2014).

Assim, com a instituição da desvinculação de receitas, o Brasil viveu um período de retrocesso entre 1994 e 2011 com a retirada de aproximadamente $\mathrm{R} \$ 80$ bilhões (oitenta bilhões de reais) da área da educação, ao longo de sua vigência. Esse fenômeno acirrou muitos problemas estruturais e pedagógicos que ainda afligem a educação pública no País, bem como o aprofundamento das desigualdades educacionais, decorrentes do investimento insuficiente na área da educação (PINTO, 2006).

Para efeito do cálculo dos recursos para MDE, o percentual de desvinculação passou para $12,5 \%$, em $2009,5 \%$, em 2010 e nulo no exercício de 2011 , quando a DRU deixou de afetar as vinculações para MDE. Destaca-se que, pela Emenda Constitucional n. 59/2009, ocorreu a recomposição dos recursos federais para a educação, ampliou-se a obrigatoriedade do ensino para a população de quatro a 17 anos, sob competência federativa dos estados (com o Ensino Médio) e dos municípios (com a Educação Infantil) e com a universalização da educação obrigatória (PINTO, 2014).

Em 2016 ocorreu nova a aprovação da DRU, agora assegurada até $2023^{4}$. A respeito disso, a Campanha Nacional pelo Direito à Educação (2016, p. 1) analisou os efeitos da DRU e constatou suas implicações nos gastos sociais que perpassaram por dois aspectos quanto à desvinculação: redução dos gastos sociais - porque apenas parte dos recursos voltam aos

Emenda à Constituição $n^{\circ} 93$ de 08 de setembro de 2016, altera o ato das disposições constitucionais transitórias para prorrogar a desvinculação de receitas da união e estabelecer a desvinculação de receitas dos estados, distrito federal e municípios. Disponível em: <http://www.planalto.gov.br/ccivil_03/constituicao/Emendas/Emc/emc93.htm>. Acesso em: 10 jul. 2020. 
Panorama Geral do Financiamento da Educação na Rede Estadual do Piauí, pós instituição do Fundeb no Brasil

setores sociais e a obtenção da meta fiscal, o que tem relação com a Lei de Responsabilidade Fiscal (LRF) (CAMPANHA NACIONAL PELO DIREITO À EDUCAÇÃO, 2016).

Considerando esses dois aspectos, a Campanha afirma que "[...] não será possível garantir acesso à educação pública com qualidade social aos brasileiros, conforme estabelece a Constituição Federal" (2016, p. 1). Pois, ao invés de aperfeiçoar este mecanismo de cooperação, fortalecendo-o com a implementação do Custo Aluno-Qualidade Inicial (CAQi), as desvinculações iriam fragilizá-lo decisivamente, pois não poderiam garantir uma educação de qualidade. Assim, é possível afirmar que o Brasil persistirá com os resultados indesejáveis que acumula ao longo de sua história na área da educação (CAMPANHA NACIONAL PELO DIREITO À EDUCAÇÃO, 2016).

Outro mecanismo legal criado foi a Lei de Responsabilidade Fiscal (LRF), Lei Complementar n.101, de 04 de maio de 2000, implementada na gestão pública como uma resposta específica e "recentralizadora" e com o desafio de coordenar o comportamento fiscal dos governos no sistema federativo. Seu objetivo principal foi garantir disciplina fiscal em todos os níveis de governo, mas, apesar de restringir também o governo federal, as restrições aos estados e municípios foram mais significativas, pois limitaram a autonomia de estados e municípios na alocação de suas receitas, sobretudo nos recursos da educação (ADRIÃO, 2016).

Um dos principais pontos da LRF diz respeito aos gastos com pessoal, nas três esferas governamentais, estabelecendo o teto para a União, que poderá gastar até $50 \%$ da sua Receita Corrente Líquida (RCL) e os estados e municípios não mais de $60 \%$. Esses gastos com pessoal da RCL afetam principalmente as despesas em educação e saúde. A gravidade dessa medida está na relação com a importância dos trabalhadores e trabalhadoras em educação para a superação da dívida social no setor, além disso, abre maior espaço para a indução a governos transferirem parte da oferta educativa para o setor privado, uma vez que o maior volume de gasto com educação decorre do pagamento de salário (ADRIÃO et al., 2009; 2014).

O estudo supracitado tem considerado que essa restrição de gasto com pessoal induz os governos a transferirem parte da oferta educativa para o setor privado, uma vez que o maior volume de gasto com educação decorre do pagamento de salário. Na mesma direção, a Associação Nacional de Pesquisa em Financiamento da Educação (FINEDUCA) declara que

[...] os efeitos perversos da Lei de Responsabilidade Fiscal (LRF n. 101/2000) nos investimentos sociais, tende a limitar e criminalizar o gasto com pessoal e impedir a garantia da qualidade dos serviços públicos, estimulando processos de privatizacão, inclusive no setor educacional (FINEDUCA, 2016).

O financiamento da educação foi também afetado pela EC n. 95/2016, que modificou o regime fiscal e impôs o congelamento de gastos públicos cujos efeitos passaram a incidir nas despesas primárias federais em 2017, tendo como referência as despesas realizadas em 2016, corrigidas pela inflação. O Teto de Gastos representa, na prática, "a desvinculação de recursos para a educação", contribuindo, portanto, para o desmonte das políticas educacionais em curso (FINEDUCA, 2016). Para a entidade, o objetivo da medida é manter o pagamento de juros e amortizações da dívida pública ao sistema financeiro e aumentar a arrecadação da União, o que atinge diretamente o serviço público e as políticas sociais e os direitos trabalhistas (FINEDUCA, 2016).

Tais medidas impactam na ampliação da obrigatoriedade e universalização da educação, porque impedem a expansão qualitativa e quantitativa das redes públicas de 
Panorama Geral do Financiamento da Educação na Rede Estadual do Piauí, pós instituição do Fundeb no Brasil

ensino. Ao mesmo tempo, na última década, vários estudos e pesquisas (ADRIÃO; PERONI, 2005; ADRIÃO, 2018; ADRIÃO et al., 2016; PERONI, 2013; CHAVES, 2015; AMARAL, 2003) evidenciam a ampliação dos processos e formas de privatização da educação em todos os níveis. Tal perspectiva também foi incorporada às preocupações da FINEDUCA

\begin{abstract}
O avanço dos setores privatistas, com suas estratégias de privatização da dinâmica escolar, já que ampliaram a valorização dos setores privados, tais como institutos e fundações vinculadas a bancos e empresas que influenciam diretamente e por cima a política educacional (FINEDUCA, 2016, p. 69).
\end{abstract}

A análise é reiterada pela Campanha Nacional pelo Direito à Educação (2016), que observa um cenário de retrocessos colocando em risco a conquista histórica da vinculação constitucional dos recursos para a educação pública, que pode ser descontinuada, caso não ocorra a revogação da EC n. 95/2016 (CAMPANHA NACIONAL PELO DIREITO À EDUCAÇÃO, 2016).

Quanto ao cumprimento do Plano Nacional de Educação (PNE 2014-2024) - Lei n. $13.005 / 14$, de 26 de junho de 2014, ele foi resultado de árdua luta da sociedade civil organizada na busca de respostas às demandas urgentes da educação pública, de forma a orientar as políticas educacionais das redes de ensino com diretrizes, metas, estratégias e condições efetivas para o alcance da educação pública de qualidade. Essas proposições foram debatidas durante as conferências municipais e estaduais de educação e aprovadas nas Conferências Nacionais de Educação (CAMPANHA NACIONAL PELO DIREITO À EDUCAÇÃO, 2016; DOURADO, 2017).

O PNE (2014-2024) é também afetado diretamente pela contenção de recursos imposta pela EC n. 95/2016, pois demanda a ampliação dos recursos para o alcance das metas definidas, sobretudo quanto ao estabelecimento da aplicação de $10 \%$ do PIB em educação, a ser atingida de maneira gradual em 10 anos, e a estratégia de definição da adoção do Custo Aluno Qualidade Inicial (CAQi) como matriz do financiamento da educação pública5 ${ }^{5}$.

Além disso, no art. 10 do PNE (2014-2024), determina-se que, no plano plurianual, as diretrizes orçamentárias e os orçamentos anuais de todos os entes da federação devam ser reformulados de maneira a assegurar a consignação de dotações orçamentárias compatíveis com as diretrizes, metas e estratégias neles estabelecidas, a fim de viabilizar sua execução (CAMPANHA NACIONAL PELO DIREITO À EDUCAÇÃO, 2016), que, no entanto, requer o aumento da participação federal.

Segundo Pinto (2012, p. 162), para cada R\$ 100 arrecadados em tributos no País, R\$ 70 é pelo governo federal, $R \$ 25$ pelos estados e, pelos municípios, apenas $R \$ 5$. Mesmo após as transferências constitucionais previstas, segundo o autor, os municípios continuam muito carentes de recursos. Essa realidade exige, nos termos de Oliveira (2007, p.19), que o centro exerça um contrapeso no sentido de implementar ações supletivas e redistributivas (CAMPANHA NACIONAL PELO DIREITO À EDUCAÇÃO, 2016), importante medida de garantia de condições para a efetivação de políticas que visam assegurar o direito à educação.

Quanto à destinação dos recursos oriundos dos Royalties do petróleo e das receitas do Fundo Social do Pré-Sal (Lei n. 12.858, de 9 de setembro de 2013) para a educação e saúde,

5 O PNE de 2014 foi antecedido pelo PNE Lei $n^{\circ}$ 10.172/2001, que não incluiu meta de aplicação do PIB em educação, devido ao veto presidencial dos $7 \%$ aprovados no Congresso Nacional. 
Panorama Geral do Financiamento da Educação na Rede Estadual do Piauí, pós instituição do Fundeb no Brasil

é uma medida importante para contribuir e reverter o atual quadro de precarização da oferta pública no País, ação que se agrega a outras iniciativas como o FUNDEB, pois se trata de uma fonte adicional relacionada à garantia de mais recursos financeiros para o cumprimento das metas estabelecidas no Plano Nacional de Educação (2014-2024).

Esse contexto de perplexidades, cortes e retrocessos coexiste com as discussões para a instituição do Novo FUNDEB, em tramitação no congresso nacional brasileiro, oportunidade em que a sociedade civil organizada propõe medidas de avanço na política de financiamento através do Fundo, considerando os seus princípios e objetivos. Para a Campanha Nacional pelo direito à educação e FINEDUCA (Nota Técnica, 2020), o novo FUNDEB deve estabelecer: 1) aumento efetivo da complementação da União e aprimoramento do sistema de distribuição dos recursos, estruturando um FUNDEB capaz de viabilizar um investimento público que colabore com a consagração do direito à educação; 2) retirada do SalárioEducação da complementação da União, sob risco de inviabilizar os programas suplementares, em especial a alimentação escolar.

Esse cenário se mostra com especificidades nas diversas realidades brasileiras. A seguir, destacamos desafios relacionados ao financiamento da educação no estado do Piauí.

\section{O Financiamento da Educação na Rede Estadual de Educação do Piauí}

O financiamento da educação no Piauí é condicionado por suas características socioeconômicas, por isso esta seção iniciará com a apresentação de alguns indicadores básicos que caracterizam o estado. Conforme a Pesquisa Nacional de Amostragem Domiciliar (PNAD) (2017), a população do Piauí foi estimada, para 2017, em 3.264.531 habitantes, sendo $49 \%$ homens e $51 \%$ mulheres. O estado possui 958.000 domicílios, com uma média de 3,3 pessoas por unidade residencial. Os dados demográficos aferidos pela PNAD (2017) indicam que o Piauí apresenta uma taxa de Mortalidade Infantil da ordem de 19,7\% de óbitos por mil nascidos vivos; uma expectativa de vida de 70,9 anos ao nascer; e uma taxa de fecundidade de 1,77 filhos por mulher (IBGE, 2017a).

Quanto ao padrão de vida no Piauí, o rendimento médio mensal domiciliar per capita, em 2018, foi de $\mathrm{R} \$ 817,00$, um pouco superior aos estados de Alagoas, Maranhão e Amazonas, os menores do Brasil. Essa renda per capita representa apenas $59,50 \%$ da renda per capita do Brasil, que é de $R \$ 1.373,00$, e $33,2 \%$ da maior renda per capita do país, a de Brasília-DF, que é R\$2.460,00 (IBGE, 2018).

Quanto ao perfil econômico, a composição setorial indica a prevalência da Administração Pública (34\%) e do setor de Serviços (31\%). Os setores constituídos pelas atividades produtivas têm indicadores que demonstram o atraso e o subdesenvolvimento do estado, uma vez que respondem por apenas 35\% da economia, sendo setor do Comércio, com 15\%, Construção Civil, com 8\%, Agropecuária, com 8\%, e Indústria de Transformação, com 4\% (IBGE, 2017a).

A população em idade escolar é de 1.254.000. No que tange ao ensino médio, a PNAD contínua de 2018 informa que $51,7 \%$ dos jovens de 15 a 17 anos estão nessa etapa de ensino; daqueles de 18 a 24 anos apenas 11,2\% cursam o Ensino Superior. Esses dados evidenciam a defasagem considerável entre as faixas etárias e as etapas ou nível de ensino. A população analfabeta de 15 anos ou mais é de 421.000 pessoas, o que constitui um índice de $12,9 \%$ de analfabetismo (IBGE, 2017a). 
Panorama Geral do Financiamento da Educação na Rede Estadual do Piauí, pós instituição do Fundeb no Brasil

No Piauí, mais de um terço de sua população encontra-se em situação de pobreza, estando bastante acima da média nacional. No Brasil, o percentual de pessoas que vive em situação de pobreza é de $15,2 \%$, enquanto no Piauí é mais do que o dobro, chegando a $34,1 \%$. Em relação aos extremamente pobres, o estado do Piauí apresenta percentual quase três vezes maior do que o percentual nacional, 18,8\% e 6,6\%, respectivamente (IBGE, 2017b).

A realidade supracitada é fruto do próprio contexto de inserção socioeconômica do estado no cenário nacional, o que faz com que ele tenha uma maior dificuldade de enfrentar seus problemas estruturais, uma vez que necessita de um maior planejamento, maior capacidade de desenvolvimento econômico e de investimentos financeiros. Além disso, as escolhas governamentais realizadas nos últimos anos corroboraram com a manutenção da perspectiva neoliberal, contribuindo para o desenvolvimento de tímidas ações de maior envergadura na oferta educacional, no financiamento e na melhoria da qualidade na área educacional e nos níveis alcançados, que ainda são insatisfatórios (PIAUÍ, 2016).

No que tange à educação, a Constituição do Estado do Piauí (CE-PI), de 1989, estabeleceu no seu art. $223^{6}$ que "[...] o Estado e seus municípios aplicarão, anualmente $30 \%$, no mínimo, da receita resultante de impostos, compreendida e proveniente de transferências, na manutenção e desenvolvimento do ensino". Nesse mesmo artigo da CE-PI essa determinação se estendeu também para as Leis Orgânicas Municipais, que passaram a definir, também, a aplicação dos recursos em educação considerando o percentual mínimo de $30 \%$ das receitas resultantes de impostos e transferências. Embora seja muito relevante esse aumento em relação aos mínimos definidos pela Constituição Federal e LDB/96, o estado do Piauí e seus municípios nunca cumpriram esse dispositivo legal, resultando em processos de iniciativa do Sindicato dos Trabalhadores e Trabalhadoras em Educação (SINTE-PI), junto ao Ministério Público, para que o governo cumpra a constituição do Estado.

Ocorre que desde 2002, sob a provocação realizada pela Prefeitura de Teresina e pela Associação Piauiense de Municípios (APPM), junto ao Tribunal de Contas do Estado do Piauí (TCE-PI), essa exigência legal foi revista, após debate interno nas diretorias técnicas do TCE/PI, as quais flexibilizaram tal exigência ao permitir que municípios cumprissem o percentual de forma progressiva em 2003. No entanto, esse ajuste também foi desconsiderado e, a partir de 2012, passou a vigorar, em definitivo, o cumprimento somente do mínimo Constitucional de $25 \%$. Essa orientação, adotada pelo TCE-PI, consta em suas instruções normativas, sem, contudo, os governantes, a Assembleia Legislativa e as câmaras municipais terem enfrentado o ônus dessa redução de $30 \%$ em suas Leis Orgânicas e na Constituição Estadual, exceto Teresina, cuja Câmara Municipal fez a mudança sem que a sociedade tivesse conhecimento e pudesse acompanhar.

A Constituição Estadual do Piauí define, ainda, a divisão dos recursos da educação na jurisprudência do Governo do estado (art. 224), destinando 25\% (vinte e cinco por cento) das receitas à Secretaria de Estado da Educação e 5\% (cinco por cento) à instituição de ensino superior mantidas pelo Estado, no caso, a Universidade Estadual do Piauí (UESPI). A forma de organização das despesas nos balanços/portal da transparência também não permite compreender as fontes que servem para a manutenção do ensino superior no estado, embora a legislação federal explicite que o investimento em outras etapas da educação é admitido

6 Governo do Estado do Piauí - Emenda Constitucional n 13, de 21 de dezembro de 2000. Disponível em: $<$ http://legislacao.pi.gov.br/legislacao/default/ato/14850>. 
Panorama Geral do Financiamento da Educação na Rede Estadual do Piauí, pós instituição do Fundeb no Brasil

somente quando atendida plenamente a responsabilidade constitucional do referido ente com a educação (no caso dos estados, ensino fundamental e médio) e ainda em percentuais superiores ao mínimo vinculado.

A EC n. 27/2008, aprovada pelo legislativo, permitiu, ainda, a utilização de até $5 \%$ do montante da receita resultante de impostos (30\%) para investimento em capacitação, qualificação e requalificação profissional e de mão de obra, ações estas que são alheias às finalidades da educação básica, estabelecendo uma "nova subvinculação" na aplicação dos mínimos constitucionais (PIAUÍ, 2008) ${ }^{7}$.

Dentre os deveres constitucionais do estado do Piauí, o direito à educação destaca-se como principal, tomando-se como referência o Plano Estadual de Educação (PEE-PI- Lei $n^{\circ}$ 6.733 , de 17 dezembro de 2015), que estabeleceu, em seu artigo $2^{\circ}$, as diretrizes para a erradicação do analfabetismo, universalização do atendimento escolar, superação das desigualdades educacionais e estabelecimento de compromisso do Estado com a educação. Para o alcance da meta de aplicação de recursos públicos em educação, a proporção de $10 \%$ vinculada ao Produto Interno Bruto (PIB) visa assegurar o atendimento às necessidades de expansão, elevação do padrão de qualidade e equidade, valorização dos(as) profissionais da educação, dentre outros (PIAUÍ, 2015).

Para o alcance desses objetivos, o Estado do Piauí conta com recursos provenientes das receitas de impostos e transferências, os quais incidem os recursos vinculados, como expressa a Tabela 1, para os anos de 2007 a 2017.

Tabela 1 - Receitas Resultantes de Impostos e Transferências (Piauí 2007-2017)

\begin{tabular}{|c|c|c|c|c|c|c|c|c|}
\hline Ano & $\begin{array}{l}\text { Receita } \\
\text { Resultante do } \\
\text { ICMS }\end{array}$ & $\begin{array}{c}\text { Receita } \\
\text { Resultante do } \\
\text { ITCD }\end{array}$ & $\begin{array}{c}\text { Receita } \\
\text { Resultante do } \\
\text { IPVA }\end{array}$ & $\begin{array}{l}\text { Receita } \\
\text { Resultante do } \\
\text { IRRF }\end{array}$ & Cota Parte FPE & $\begin{array}{r}\text { L.C. n. } \\
87 / 1996\end{array}$ & $\begin{array}{l}\text { Cota Parte } \\
\text { IPI Exp }\end{array}$ & Total \\
\hline 2007 & $2.191 .395 .239,24$ & $.489 .337,53$ & $119.669 .308,65$ & $169.037 .190,64$ & $3.150 .171 .041,14$ & $8.373 .050,14$ & $1.742 .284,28$ & $5.644 .877 .451,61$ \\
\hline 2008 & $2.538 .613 .346,55$ & $6.287 .852,79$ & $137.927 .581,15$ & $193.709 .942,57$ & $3.662 .557 .783,79$ & $7.962 .525,49$ & $1.818 .196,83$ & $6.548 .877 .229,17$ \\
\hline 2009 & $2.681 .108 .734,25$ & $3.908 .133,62$ & $148.735 .469,33$ & $186.776 .523,91$ & $3.315 .107 .630,81$ & $7.477 .852,22$ & $1.389 .621,23$ & $6.344 .503 .965,37$ \\
\hline 2010 & $3.116 .401 .766,49$ & $6.697 .053,28$ & $168.162 .883,61$ & $220.283 .518,43$ & $3.431 .917 .065,85$ & $7.182 .384,54$ & $2.078 .114,73$ & $6.952 .722 .786,93$ \\
\hline 2011 & $3.186 .923 .736,29$ & $7.420 .650,63$ & $187.628 .730,66$ & $241.924 .434,71$ & $3.970 .745 .967,26$ & $6.746 .227,29$ & $2.191 .813,41$ & 7.603.581.560,26 \\
\hline 2012 & $3.437 .847 .249,42$ & $15.525 .869,27$ & $204.724 .402,30$ & $243.653 .315,63$ & $3.859 .524 .230,00$ & $6.359 .572,07$ & $1.378 .484,73$ & $7.769 .013 .123,43$ \\
\hline 2013 & $3.624 .827 .765,30$ & $16.538 .831,79$ & $227.340 .524,27$ & $288.466 .070,73$ & $3.908 .488 .804,85$ & $5.988 .422,40$ & $1.155 .661,29$ & $8.072 .806 .080,63$ \\
\hline 2014 & $3.823 .274 .904,23$ & $23.036 .093,33$ & $248.815 .013,75$ & $318.530 .409,00$ & $4.034 .688 .449,34$ & $5.672 .860,19$ & $1.267 .726,26$ & $8.455 .285 .456,10$ \\
\hline 2015 & 3.892.399.176,70 & $20.541 .041,16$ & $264.981 .686,82$ & $357.199 .322,77$ & $3.995 .572 .114,11$ & $5.340 .254,95$ & $1.324 .365,87$ & $8.537 .357 .962,37$ \\
\hline 2016 & $3.729 .642 .175,47$ & $15.682 .519,29$ & $277.892 .979,97$ & $363.487 .012,36$ & $4.104 .100 .116,75$ & $4.799 .100,44$ & $1.095 .383,29$ & $8.496 .699 .287,57$ \\
\hline 2017 & $3.868 .914 .435,16$ & $13.870 .128,69$ & $276.920 .554,98$ & $391.666 .034,04$ & $3.670 .353 .864,61$ & $4.502 .816,61$ & $1.244 .894,97$ & $8.227 .472 .729,08$ \\
\hline
\end{tabular}

Nota: Valores corrigidos pelo INPC/IBGE de dez/2017 em valores reais.

Fonte: Relatório Resumido de Receitas Orçamentárias - SIOPE e SEFAZ.

De forma geral, houve crescimento das Receitas Orçamentárias do estado do Piauí, de 2007 para 2017 , de 29,4\%. Verifica-se que, dentre as receitas de impostos e transferências

7 Governo do Estado do Piauí - Emenda Constitucional $n^{\circ} 27$, de 17 de dezembro de 2008. Disponível em: <http://legislacao.pi.gov.br/legislacao/default/ato/14853>. 
Panorama Geral do Financiamento da Educação na Rede Estadual do Piauí, pós instituição do Fundeb no Brasil

constitucionais, o Fundo de Participação do Estado (FPE) e o Imposto de Circulação de Mercadorias (ICMS) destacaram-se com uma maior participação na receita, com $50 \%$ e $44 \%$, respectivamente, do total de recursos de 2007 a 2017. O ICMS teve crescimento real (INPC) durante a série histórica de $77 \%$, apresentando queda apenas em 2015 e 2016. Já o FPE apresentou um crescimento de 17\%, com quedas acentuadas nos períodos de 2009, 2010, 2015 e 2017. Dessa forma, observa-se que a receita do ICMS ultrapassou o FPE em 2017. Também cresceram significativamente o ITCMD (209\%), o IPVA (131\%) e o IRRF (132\%), embora tenham sido muito pouco significativos percentualmente na composição da receita, com média de 0,16\%, 2,74\% e 3,60\%, respectivamente, de 2007 a 2017.

Os recursos de impostos e transferências são a base do Gráfico 1, a seguir, que expressa os percentuais aplicados em educação na Manutenção e Desenvolvimento de Ensino na rede estadual de educação do Piauí.

\section{Gráfico 1 - Aplicação do valor mínimo Constitucional em MDE da SEDUC - Piauí (2006-2016)}

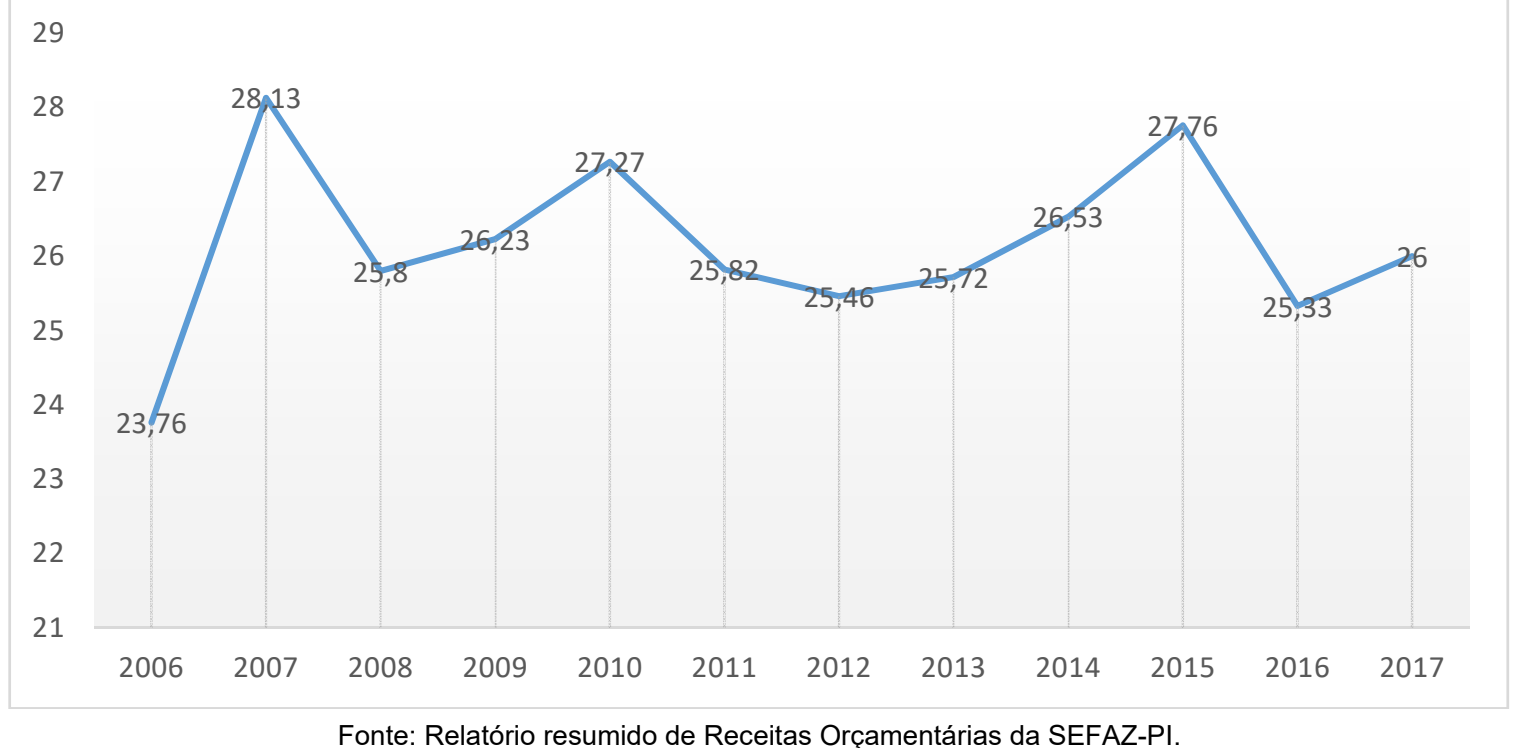

O Gráfico 1 expressa que, de 2007 para 2017, houve a aplicação do percentual mínimo de recursos em MDE nos limites definidos pela CF/88. Os anos de maior investimento foram 2007 (28,13\%), $2010(27,27 \%)$ e 2015 (27,76\%). Entretanto, isso não significou mais recursos, porque em 2010 e 2015 houve queda nas receitas do estado. Os anos em que a aplicação em MDE ficou bem próxima dos limites constitucionais foram 2012 (25,46\%) e 2016 (25,33\%). De acordo com o Gráfico 1, o percentual mínimo, em 2006, foi de apenas $23,76 \%$, não cumprindo o que estabelece a CF/88, mínimo de 25\% (Art. 212 CF/88), o que é cobrado pelo TCE/PI na fiscalização do limite mínimo constitucional. Se o TCE/PI cumprisse com o prescrito na Constituição Estadual do Piauí, que estabelece o percentual mínimo de 30\% das receitas resultantes de impostos e transferências a ser aplicado em MDE (Art. 223, CE/PI), o Piauí teria suas contas reprovadas em todos os anos de análise.

No que se refere às despesas, considerando a contribuição e o retorno dos recursos na partilha e na complementação da União ao FUNDEB, a Tabela 2 expressa o movimento de 2007 a 2017. 
Panorama Geral do Financiamento da Educação na Rede Estadual do Piauí, pós instituição do Fundeb no Brasil

Tabela 2 - Informações Orçamentárias do estado do Piauí, 2007 - 2017

\begin{tabular}{cccccc}
\hline Ano & $\begin{array}{c}\text { Total Despesa com } \\
\text { Ações Típicas de } \\
\text { MDE }\end{array}$ & $\begin{array}{c}\text { Recursos do Fundeb } \\
\text { (destinado) }\end{array}$ & $\begin{array}{c}\text { Recursos do } \\
\text { Fundeb (recebidos) }\end{array}$ & $\begin{array}{c}\text { Complementação da } \\
\text { União }\end{array}$ & Perda do Fundeb \\
\hline 2007 & $977.641 .894,49$ & $772.811 .179,30$ & $396.848 .972,76$ & $53.227 .086,05$ & $429.189 .292,59$ \\
2008 & $1.003 .690 .306,43$ & $975.880 .485,04$ & $533.901 .681,63$ & $71.533 .483,12$ & $513.514 .765,79$ \\
2009 & $1.114 .172 .083,10$ & $1.046 .420 .627,72$ & $729.871 .070,70$ & $157.244 .497,58$ & $474.663 .622,38$ \\
2010 & $1.187 .690 .606,53$ & $1.095 .127 .164,18$ & $712.745 .129,51$ & $144.711 .745,83$ & $527.233 .585,34$ \\
2011 & $1.307 .153 .857,85$ & $1.211 .950 .036,86$ & $864.385 .453,67$ & $192.415 .307,62$ & $541.423 .514,04$ \\
2012 & $1.339 .929 .662,17$ & $1.229 .408 .808,20$ & $846.344 .748,20$ & $183.383 .126,40$ & $567.449 .557,67$ \\
2013 & $1.423 .295 .668,11$ & $1.284 .894 .811,86$ & $831.583 .476,94$ & $160.384 .336,19$ & $615.273 .664,25$ \\
2014 & $1.326 .925 .813,73$ & $1.331 .067 .495,52$ & $783.209 .009,75$ & $142.999 .926,57$ & $692.526 .682,25$ \\
2015 & $1.328 .348 .172,74$ & $1.277 .832 .838,63$ & $718.044 .154,07$ & $137.087 .361,54$ & $702.596 .805,04$ \\
2016 & $1.215 .645 .811,39$ & $1.316 .327 .392,25$ & $759.739 .805,45$ & $165.053 .660,01$ & $723.773 .718,08$ \\
2017 & $1.390 .358 .673,44$ & $1.325 .898 .048,20$ & $862.336 .973,94$ & $207.347 .772,59$ & $676.447 .753,17$ \\
\hline$\%$ & $42,20 \%$ & $71,60 \%$ & $117,30 \%$ & $289,60 \%$ & $57,60 \%$ \\
\hline
\end{tabular}

Fonte: Relatório resumido de Receitas Orçamentárias da SEFAZ-PI, 2017.

A Tabela 2 indica crescimento de $289 \%$ na complementação da União de 2007 para 2017, representando um aumento considerável, decorrente do escalonamento em quatro anos da implantação dos 10\% na aplicação do FUNDEB (2007 a 2010) e do movimento próprio de atualização dos valores do Fundo. Destaca-se, ainda, o crescimento $71,6 \%$ das receitas destinadas ao FUNDEB e de $117,3 \%$ nas receitas recebidas pelo Fundo. Contudo, verifica-se nesse período um processo intenso de municipalização, por iniciativa do governo do estado do Piauí, com reflexo direto na receita de recursos do FUNDEB recebida pela rede estadual de educação. No período de 2007 a 2017, houve crescimento acentuado das receitas próprias do estado, cujo percentual de crescimento, conforme Tabela 1, resultou em 29,4\%.

No entanto, no movimento de contribuição ao FUNDEB e retorno dos recursos, a rede estadual de educação do Piauí teve perdas crescentes. Mesmo se considerando o aumento da complementação da União; o crescimento do valor aluno ano do FUNDEB (60,7\% de 2007 para 2017) e a inclusão de novas matrículas do ensino médio, a rede estadual, ainda assim, acumulou um déficit (perdas) de $57,6 \%$ no período analisado.

Assim, a rede estadual de educação do Piauí tem acumulado, a cada ano, perdas significativas de recursos no FUNDEB, do ponto de vista financeiro, que podem ser atribuídas a dois fatores principais: 1) o fato de possuir uma arrecadação maior do que a dos municípios, o que faz com que o valor destinado do estado ao Fundo seja muito maior do que aquele que retorna, após a aplicação dos critérios de repartição do Fundo estadual; 2) a queda do número de matrículas no ensino fundamental estadual, decorrente do processo de municipalização.

8 Valores atualizados pelo INPC (dezembro de 2017). 
Panorama Geral do Financiamento da Educação na Rede Estadual do Piauí, pós instituição do Fundeb no Brasil

\section{Considerações Finais}

As políticas educacionais, como aquelas voltadas à efetivação do direito à educação, dependem da ação sistemática do Estado brasileiro e da sociedade para reivindicar que elas sejam compatíveis com os seus interesses, transformações e necessidades, uma vez que o amparo legal não é suficiente para a sua garantia. No entanto, deve-se reconhecer a importância das conquistas na Constituição Federal de 1988 e na legislação brasileira complementar mediante a garantia da oferta educativa, da obrigatoriedade e do financiamento da educação.

Este artigo apresentou questões que afetaram o financiamento da educação no Brasil desde a CF/1988. Assim como se analisou o financiamento da educação na rede estadual do Piauí. Quanto à análise financeira das receitas e despesas em educação, constatou-se que os recursos destinados à educação na rede estadual do Piauí, de 2007 para 2017, tiveram um aumento real de $18,9 \%$, com variações e quedas ao longo desse período.

Esse mesmo movimento também pôde ser verificado na aplicação percentual de recursos em Manutenção e Desenvolvimento do Ensino, isso porque, embora tenha ocorrido alguma variação, o estado nunca alcançou os $30 \%$ estabelecidos na sua própria Constituição, ficando no limite dos $25 \%$ definidos na Constituição Federal. Os anos de maior investimento foram 2007, 2010 e 2015, no entanto, isso não significa mais recursos, pois em 2010 e 2015 houve queda nas receitas do estado. Os anos em que a aplicação em MDE ficou bem próxima dos limites constitucionais de 25\% foram 2012 e 2016.

No que tange ao FUNDEB, em relação ao processo de redistribuição interna dos recursos arrecadados, a Rede Pública Estadual do Piauí redistribuiu mais do que recebeu de recursos resultantes das receitas líquidas de impostos vinculados ao FUNDEB, no período de 2007 a 2017, tendo perdas significativas no sistema de partilha, cujos valores não foram compensados pela complementação da União.

A política de fundo foi importante, requerendo, sobretudo, em vistas a sua continuidade com o Novo FUNDEB, a ampliação da participação da União na complementação e o aprimoramento do sistema de distribuição dos recursos, cujo Custo Aluno-Qualidade Inicial (CAQi) e Custo Aluno-Qualidade (CAQ), previsto no Plano Nacional de Educação, são referências importantes para o alcance do padrão mínimo de qualidade.

\section{Referências}

ADRIÃO, T. et al. Grupos empresariais na educação básica pública brasileira: limites à efetivação do direito à educação. Educação \& Sociedade, Campinas, v. 37, n. 134, p. 113131, 2016. Disponível em: <https://dx.doi.org/10.1590/ES0101-73302016157605>. Acesso em: 10 fev. 2020.

ADRIÃO, T. Dimensões e Formas da Privatização da Educação no Brasil: caracterização a partir de mapeamento de produções nacionais e internacionais. Currículo sem Fronteiras, v. 18, n. 1, p. 8-28, jan./abr. 2018. Disponível em: <http://www.curriculosemfronteiras.org/v ol18iss1articles/adriao.pdf>. Acesso em: 3 maio 2020. 
Panorama Geral do Financiamento da Educação na Rede Estadual do Piauí, pós instituição do Fundeb no Brasil

ADRIÃO, T. et al. Uma modalidade peculiar de privatização da educação pública: a aquisição de "sistemas de ensino" por municípios paulistas. Educação \& Sociedade, Campinas. v. 30, n. 108, p. 799-818, out. 2009.

ADRIÃO, T.; GARCIA, T. O. Subsídio público ao setor privado: reflexões sobre a gestão da escola pública no Brasil. Políticas Educativas, v. 7, p. 110-122, 2014.

ADRIÃO, T.; PERONI, V. (Org.). O público e o privado na educação: interfaces entre Estado e Sociedade. São Paulo: Xamã, 2005. p. 137-166.

AMARAL, N. C. Financiamento da educação superior: estado x mercado. São Paulo: Cortez; Piracicaba: UNIMEP, 2003.

BRASIL. Constituição (1988). Constituição da República Federativa do Brasil. Promulgada em 5 de outubro de 1988. Diário Oficial da União, Brasília, DF, 1988. Disponível em: <http://www.planalto.gov.br/ccivil_03/Constituicao/ConstituicaoCompilado.htm>. Acesso em: 13 maio 2020.

BRASIL. Emenda Constitucional n. 14, de 12/09/ 1996. Modifica os arts. 34, 208, 211 e 212 da Constituição Federal e dá nova redação ao art. 60 do Ato das Disposições Constitucionais Transitórias. Diário Oficial da União, Brasília, 13 set. 1996a.

BRASIL. Lei n. 9.394, de 20/12/1996. Lei de Diretrizes e Bases da Educação Nacional. Diário Oficial da União, Brasília, 23 dez. 1996b. Seção I, p. 27833-27841. Disponível em: <http://ww w.planalto.gov.br/ccivil_03/leis/l9394.htm>. Acesso em: 13 maio 2020.

BRASIL. Lei n. 9424, de 24/12/1996. Dispõe sobre o Fundo de Manutenção e Desenvolvimento do Ensino Fundamental e de Valorização do Magistério, na forma prevista no Art. $60 \S 7^{\circ}$ do Ato das Disposições Constitucionais Transitórias, e dá outras providências. Diário Oficial da União, Brasília, 26 dez. 1996c.

BRASIL. Lei Complementar n. 101, de 4 de maio de 2000. Estabelece normas de finanças públicas voltadas para a responsabilidade na gestão fiscal e dá outras providências. Diário Oficial da União, Brasília, 2000.

BRASIL. Emenda constitucional n. 53, de 19 de dezembro de 2006. Diário Oficial da União, Brasília, DF, 20 dez. 2006.

BRASIL. Lei n. 11.494, de 20 de junho de 2007. Regulamenta o Fundo de Manutenção e Desenvolvimento da Educação Básica e de Valorização dos Profissionais da Educação FUNDEB; revoga dispositivos das Leis n. 9.424, de 24 de dezembro de 1996, 10.880, de 9 de junho de 2004, e 10.845, de 5 de março de 2004; e dá outras providências. Diário Oficial da União, Brasília, 2007a. Disponível em: <http://www.planalto.gov.br/ccivil_03/_ato20072010/2007/lei/l11494.htm>. Acesso em: 1 maio 2020.

BRASIL. Decreto n. 6.253, de 13 de novembro de 2007. Dispõe sobre o Fundo de Manutenção e Desenvolvimento da Educação Básica e de Valorização dos Profissionais da Educação FUNDEB, regulamenta a Lei n. 11.494, de 20 de junho de 2007, e dá outras providências. Diário Oficial da União, Brasília, 2007b. Disponível em: <http://www.planalto.gov.br/ ccivil_03/_ato2007-2010/2007/decreto/d6253.htm>. Acesso em: 25 abr. 2020. 
Panorama Geral do Financiamento da Educação na Rede Estadual do Piauí, pós instituição do Fundeb no Brasil

BRASIL. Emenda constitucional n. 59, de 11 de novembro de 2009. Diário Oficial da União, Brasília, DF, 12 nov. 2009. p. 8.

BRASIL. Lei n. 13.005, de 25 de junho de 2014. Aprova o Plano Nacional de Educação - PNE e dá outras providências. Diário Oficial da União, Brasília, DF, 25 jun. 2014. Disponível em: <http://www.planalto.gov.br/ccivil_03/_ato2011-2014/2014/lei//13005.htm>. Acesso em: 01 mar. 2020.

BRASIL. Emenda Constitucional 95/2016. Altera o Ato das Disposições Constitucionais Transitórias, para instituir o Novo Regime Fiscal. Diário Oficial da União, Brasília, 2016. Disponível em: <https://goo.gl/krEA9g>. Acesso em: 5 abr. 2020.

BRASIL. Sistema de Informações sobre Orçamentos Públicos em Educação (SIOPE). Brasília, 2020. Disponível em: <https://www.fnde.gov.br/fnde_sistemas/siope>. Acesso em: 26 maio 2020.

CAMPANHA NACIONAL PELO DIREITO À EDUCAÇÃO. Quem somos. São Paulo, 2016. Disponível em: <http://campanha.org.br/quem-somos/a-campanha/>. Acesso em: 05 fev. 2020.

CASTRO, J. A. As desigualdades regionais no sistema educacional brasileiro. In: HENRIQUES, R. (Org.). Desigualdade e pobreza no Brasil. Rio de Janeiro: Ipea, 2000. p. 425-458.

CASTRO, J. A. Financiamento da Educação. Em Aberto, Brasília, v. 16, n. 74, dez. 2001. Disponível em: <http://www.dominiopublico.gov.br/download/texto/me001406.pdf>. Acesso em: 03 fev. 2020.

CHAVES, V. L. J. Política de financiamento e a expansão da educação superior no Brasil: o público e o privado em questão. Educação Temática Digital, Campinas, v. 17, n. 2, p. 427 441, 2015.

CURY, C. R. J. A Educação Básica no Brasil. Educação \& Sociedade, Campinas, v. 23, n. 80, p. 168-200, set. 2002.

CURY, C. R. J. A gestão democrática na escola e o direito à educação. Revista Brasileira de política e Administração da Educação (RBPAE), Porto Alegre, v. 23, n. 3, p. 483-495, set./dez. 2007.

DAVIES, N. Fundeb: a redenção da educação básica?. Educação \& Sociedade, Campinas, v. 27, n.96, p. 753-776, 2006.

DOURADO, L. F. Plano Nacional de Educação: o epicentro das políticas de estado para educação brasileira. Goiânia: Editora Imprensa Universitária, ANPAE, 2017.

FINEDUCA. Carta de São Paulo. In: ENCONTRO FINEDUCA, 4., 2016, São Paulo. Apresentação. São Paulo, 18 ago. 2016. Disponível em: <http://fineduca.org.br/2016/08 /18/carta-de-sao-paulo-iv-encontro-fineduca/_CNDE_01_2018.pdf>. Acesso em: 6 jun. 2020.

FÓRUM 21. Austeridade e retrocesso - Finanças públicas e política fiscal no Brasil. São Paulo: Fundação Friedrich Ebert Stiftung (FES); GT de Macro da Sociedade Brasileira de Economia Política (SEP); Plataforma Política Social, set. 2016. 
Panorama Geral do Financiamento da Educação na Rede Estadual do Piauí, pós instituição do Fundeb no Brasil

IBGE. Cidades. Habitantes do Piauí. Rio de Janeiro, 2017a. Disponível em: <http://cidades.ibge.gov.br/xtras/perfil.php?codmun=221100>. Acesso em: 5 fev. 2020.

IBGE. Síntese de indicadores sociais. Uma análise das condições de vida da população brasileira. Estudos e pesquisas - Informação demográfica e socioeconômica, n. 35, 2017b. Disponível em: <http://biblioteca.ibge.gov.br/visualizacao/livros/liv95011.pdf>. Acesso em: 19 jun. 2020.

IBGE. Cidades. Projeção da população do Brasil por sexo e idade para o período. Rio de Janeiro, 2018. Disponível em: <http://cidades.ibge.gov.br/xtras/perfil.php?codmun=221100>. Acesso em: 5 fev. 2020.

IBGE. IDADOS. Rio de Janeiro. Disponível em: <https://sidra.ibge.gov.br/home/pms/brasil>. Acesso em: 2 abr. 2017.

MELCHIOR, J. C. A. O financiamento da educação no Brasil. São Paulo: EPU, 1987

OLIVEIRA, R. P. Financiamento da educação no Brasil. In: OLIVEIRA, R. P.; ADRIÃO, T. (Org.). Gestão, financiamento e direito à educação: Análise da LDB e da Constituição Federal. 3. ed. São Paulo: Xamã, 2007.

PERONI, V. M. V. As relações entre o público e o privado nas políticas educacionais no contexto da Terceira Via. Currículo sem Fronteiras, v. 13, n. 2, p. 234-255, maio/ago. 2013.

PIAUÍ. Constituição do Estado do Piauí. Diário Oficial do Estado, Teresina, 1989. Disponível em: <http://www2.senado.leg.br/bdsf/bitstream/handle/id/70447/CE_Piaui.pdf?sequence=8>. Acesso em: 03 mar. 2020.

PIAUÍ. Tribunal de Contas do Estado. Despesas com Manutenção e Desenvolvimento do Ensino (Resoluções Normativas). Teresina: TCE, jun. 1998.

PIAUÍ. Governo do Estado do Piauí. Emenda Constitucional № 13 de 21 de dezembro de 2000. Diário Oficial do Estado, Teresina, 2000. Disponível em <http://legislacao.pi.gov. br/legislacao/default/ato/14850>. Acesso em: 23 abr. 2020.

PIAUÍ. Secretaria da Fazenda. Balanço Geral do Estado de 1996 a 2009. Teresina, 2010. Disponível em: <http://www.sefaz_pi.gov.br>. Acesso em: 20 maio 2020.

PIAUÍ. Plano Estadual de Educação (2015-2025). Diário Oficial do Estado, Teresina, 2015. Disponível em: <http://leisdopiaui.com/single-post/2017/03/04/Lei-673315---Plano-Estadualde-Educação>. Acesso em: 03 mar. 2020.

PINTO, J. M. R. Os Recursos para Educação no Brasil no contexto das finanças públicas. Brasília: Ed. Plano, 2000.

PINTO, J. M. R. Financiamento da educação no Brasil: um balanço do governo FHC (19952002). Educação \& Sociedade, Campinas, v. 23, n. 80, p. 108-135, set. 2002.

PINTO, J. M. R. Uma proposta de custo-aluno-qualidade na educação básica. Revista Brasileira de Política e Administração da Educação, v. 22, p. 197-227, 2006.

PINTO, J. M. R.. A política recente de fundos para o financiamento da educação e seus efeitos no pacto federativo. Educação \& Sociedade, Campinas, v. 28, p. 877-897, 2007. 
Panorama Geral do Financiamento da Educação na Rede Estadual do Piauí, pós instituição do Fundeb no Brasil

PINTO, J. M. R. Quanto custa financiar um "PNE pra Valer"? Educação \& Sociedade, Campinas, v. 27, n. 94, p. 47-69, jan./abr. 2011.

PINTO, J. M. R. Para onde vai o dinheiro? caminhos e descaminhos do financiamento da educação. São Paulo: Xamã, 2014.

PINTO, J. M. R. Uma Análise da Destinação dos Recursos Públicos, Direta ou Indiretamente, ao Setor Privado de Ensino no Brasil. Educação \& Sociedade, Campinas, v. 37, p. 133-152, 2016.

PINTO, J. M. R. O Financiamento da Educação na Constituição Federal De 1988: 30 Anos de Mobilização Social. Educação \& Sociedade, Campinas, v. 39, p. 1-24, 2018.

PINTO, J. M. R.; ADRIÃO, T. Noções gerais sobre o financiamento da educação no Brasil. EcoS - Revista Científica, São Paulo, v. 8, n. 1, p. 23-46, jan./jun. 2006.

PINTO, J. M. R; CARA, D.; ARAÚJO, L. Nota técnica 01/2013: Por que a União deve complementar o CAQi no PNE? São Paulo: Fineduca, 2013.

SALES, L. C.; SILVA, M. J. O financiamento da educação pública municipal de Teresina: o custo-aluno/ano. Ensaio Avaliação Políticas Públicas Educacionais, Rio de Janeiro, v. 17, n. 65, p. 695-718, out./dez. 2009.

SILVA, S. de O. Política Educacional para o Ensino Médio na Rede Estadual do Piauí: limites do atendimento e das condições de oferta para a garantia do direito à educação no contexto do Fundeb. 2019. Orientação: Theresa Maria de Freitas Adrião. Tese (Doutorado em Educação) - Universidade Estadual de Campinas, Campinas, 2019.

Samara de Oliveira Silva é doutora em Educação - FE- UNICAMP, Mestre em Educação pela UFPI, Graduada em Licenciatura Plena em Pedagogia, Especialista em Psicologia da Educação. Atualmente é professora da Universidade Estadual do Piauí, pesquisadora colaboradora do Núcleo de Estudos e Pesquisas em Políticas Educacionais e Gestão da Educação-NUPPEGE (UFPI), membro do Núcleo de Estudos em Educação e Sociedade NEPES/ UESPI e pesquisadora colaboradora do Núcleo de Estudos e Pesquisas em Políticas Educacionais (GREPPE - UNICAMP).

ORCID: https://orcid.org/0000-0002-3578-9940

E-mail: sossamdoc@gmail.com

Theresa Maria de Freitas Adrião graduada em Pedagogia pela Universidade de São Paulo (1988), mestrado em Educação pela Universidade de São Paulo (1995) e doutorado em Educação pela Universidade de São Paulo (2001) e Livre Docente pela UNICAMP. É professora e pesquisadora do Programa de Pós-Graduação da UNICAMP. Realizou estágios pós-doutorais de pesquisa na OREALC/UNESCO (2004-2005) na Universidade de Maryland apoio Fapesp/2013-2014); na Universidade do Minho (2015/2016). Desenvolve e pesquisas na área de política educacional, com ênfase em gestão e financiamento da educação básica, incluindo estudos sobre privatização. Publicou diversos livros e artigos sobre os temas de investigação.

ORCID: https://orcid.org/0000-0003-1181-5873

E-mail: theadriao@gmail.com 
Panorama Geral do Financiamento da Educação na Rede Estadual do Piauí, pós instituição do Fundeb no Brasil

Lucine Rodrigues Vasconcelos Borges de Almeida possui graduação em Pedagogia pela Universidade Estadual do Maranhão UEMA (1988), é Pós-Graduada em Gestão Pública (2007). Professora da Rede Estadual do Estado do Piauí. Atualmente é pesquisadora colaboradora do Núcleo de Estudos e Pesquisas em Políticas Educacionais e Gestão da Educação -NUPPEGE da Universidade Federal do Piauí sob a coordenação da Prof. ${ }^{a}$ Dr. $^{a}$ Rosana Evangelista da Cruz.

ORCID: https://orcid.org/0000-0003-1181-5873

E-mail: lucinerodrigues@yahoo.com.br

Recebido em 28 de abril de 2020

Aprovado em 21 de julho de 2020 


\section{Editores do volume 10}

Márcia Aparecida Jacomini - Universidade Federal de São Paulo, Brasil

José Marcelino de Rezende Pinto - Universidade de São Paulo, Brasil

\section{Comitê Editorial}

Nalú Farenzena - Universidade Federal do Rio Grande do Sul, Brasil

Juca Gil - Universidade Federal do Rio Grande do Sul, Brasil

Theresa Adrião - Universidade Estadual de Campinas, Brasil

Ângelo Ricardo de Souza - Universidade Federal do Paraná, Brasil

\section{Conselho Editorial}

\section{Alejandro Morduchowicz}

Universidad Pedagógica, Provincia de Buenos Aires, Argentina

Andréa Barbosa Gouveia

Universidade Federal do Paraná, Brasil

Fernanda Saforcada

Universidade de Buenos Aires, Argentina

Jacques Velloso

Universidade de Brasília, Brasil

João Monlevade

Senado Federal, Brasil

Jorge Abrahão de Castro

Instituto de Pesquisa Econômica Aplicada / IPEA, Brasil

Lisete Regina Gomes Arelaro

Universidade de São Paulo, Brasil

Luis Carlos Sales

Universidade Federal do Piauí, Brasil

Luiz de Sousa Junior

Universidade Federal da Paraíba, Brasil

Luiz Fernandes Dourado

Universidade Federal de Goiás, Brasil

Magna França

Universidade Federal do Rio Grande do Norte, Brasil

Marcos Edgar Bassi

Universidade Federal de Santa Catarina, Brasil

Maria Angélica Pedra Minhoto

Universidade Federal de São Paulo, Brasil

Maria Beatriz Luce

Universidade Federal do Rio Grande do Sul, Brasil

Maria Dilnéia Espíndola Fernandes

Universidade Federal de Mato Grosso do Sul, Brasil

Nelson Cardoso do Amaral

Universidade Federal de Goiás, Brasil

Nicholas Davies

Universidade Federal Fluminense, Brasil

Robert E. Verhine

Universidade Federal da Bahia, Brasil

Romualdo Portela de Oliveira

Universidade de São Paulo, Brasil

Rosana Gemaque Rolim

Universidade Federal do Pará, Brasil

Rubens Barbosa de Camargo

Universidade de São Paulo, Brasil

Theresa Adrião

Universidade Estadual de Campinas, Brasil

Tristan McCowan

University of London, Reino Unido

Vera Jacob

Universidade Federal do Pará, Brasil

Vera Peroni

Universidade Federal do Rio Grande do Sul, Brasil

Vitor Henrique Paro

Universidade de São Paulo, Brasil

\section{Equipe editorial}

Apoio ao Comitê Editorial: Caio Cabral da Silva

Diagramação, Revisão de português e normalização: Edson Leonel de Oliveira

Revisão de inglês: Sabrina Ferreira

Fineduca - Revista de Financiamento da Educação

Associação Nacional de Pesquisa em

Financiamento da Educação

e-mail: revista.fineduca@gmail.com | site: http://seer.ufrgs.br/fineduca 